\title{
Comprehensive analysis of targetable oncogenic mutations in chinese cervical cancers
}

\author{
Libing Xiang ${ }^{1}$, Jiajia Li ${ }^{1}$, Wei Jiang ${ }^{1}$, Xuxia Shen ${ }^{2}$, Wentao Yang ${ }^{2}$, Xiaohua Wu ${ }^{1}$ and \\ Huijuan Yang ${ }^{1}$ \\ 1 Department of Gynecological Oncology, Fudan University Shanghai Cancer Center, Department of Oncology, Shanghai \\ Medical College, Fudan University, Shanghai, China \\ 2 Department of Pathology, Fudan University Shanghai Cancer Center, Department of Oncology, Shanghai Medical College, \\ Fudan University, Shanghai, China \\ Correspondence to: Huijuan Yang, email: huijuanyang@hotmail.com \\ Keywords: Oncogenic mutation, Cervical cancers, PI3K pathway genes, RTK genes, RAS genes \\ Received: November 01,2014 Accepted: December 27,2014 Published: December 31, 2014
}

This is an open-access article distributed under the terms of the Creative Commons Attribution License, which permits unrestricted use, distribution, and reproduction in any medium, provided the original author and source are credited.

\section{ABSTRACT}

Mutations in 16 targetable oncogenic genes were examined using reverse transcription polymerase chain reaction (RT-PCR) and direct sequencing in 285 Chinese cervical cancers. Their clinicopathological relevance and prognostic significance was assessed. Ninety-two nonsynonymous somatic mutations were identified in $\mathbf{2 9 . 8 \%}$ of the cancers. The mutation rates were as follows: PIK3CA (12.3\%), KRAS (5.3\%), HER2 (4.2\%), FGFR3-TACC3 fusions (3.9\%), PTEN (2.8\%), FGFR2 $(1.8 \%)$, FGFR3 $(0.7 \%)$, NRAS $(0.7 \%)$, HRAS $(0.4 \%)$ and EGFR $(0.4 \%)$. No mutations were detected in AKT1 or BRAF, and the fusions FGFR1-TACC1, EML4$A L K$, CCDC6-RET and KIF5B-RET were not found in any of the cancers. RTK and RAS mutations were more common in non-squamous carcinomas than in squamous carcinomas $(P=0.043$ and $P=0.042$, respectively). $R A S$ mutations were more common in young patients ( $<45$ years) $(13.7 \%$ vs. $7.7 \%, P=0.027) . R T K$ mutations tended to be more common in young patients, whereas PIK3CA/PTEN/AKT mutations tended to be more common in old patients. RAS mutations were significantly associated with disease relapse. To our knowledge, this is the first comprehensive analysis of major targetable oncogenic mutations in a large cohort of cervical cancer cases. Our data reveal that a considerable proportion of patients with cervical cancers harbor known druggable mutations and might benefit from targeted therapy.

\section{INTRODUCTION}

Cervical cancer is the seventh most common and the eighth deadliest cancer in Chinese women. In 2010, it affected approximately 77,000 women and killed over 21,000 women in China [1]. Current treatment protocols for invasive cervical cancer are mostly based on surgery and chemoradiotherapy. Despite improved multidisciplinary treatment, the prognosis of advanced/ recurrent cervical cancer is still poor, with a median overall survival (OS) ranging between 10 and 13 months [2].

A detailed understanding of somatic mutations in genes that encode signaling proteins with crucial roles in cellular proliferation and survival has led to the development of highly specific inhibitors that target key oncogenic pathways. Recently, molecularly targeted therapies have dramatically improved the treatment outcomes in patients whose tumors harbor activated mutant kinases such as mutant EGFR, BRAF and HER2 or translocated ALK [3-7]. The identification of such "druggable" mutant kinases in human cancer is becoming increasingly important. However, the question of whether cervical cancers harbor identifiable driver oncogenic mutations and benefit from targeted therapy has remained largely unanswered. Neither the prevalence of activating mutations nor the relevant clinicopathological characteristics are well established, and these factors are of paramount importance in the design of clinical trials for advanced or recurrent cervical cancers. 
To investigate such "druggable" oncogenic genetic alterations in cervical cancer, we examined the mutational status of 16 oncogenic genes-KRAS, NRAS, HRAS, BRAF, PIK3CA, PTEN, AKT1, HER2, EGFR, FGFR2 and FGFR3 as well as FGFR3-TACC3, FGFR1-TACC1, EML4-ALK, CCDC6-RET and KIF5B-RET fusions-in a cohort of 285 Chinese patients with resected cervical cancer using reverse transcription polymerase chain reaction (RT-PCR) and direct sequencing.

\section{RESULTS}

Tumors from 285 Chinese patients with cervical cancer were examined, including 179 patients with SCCs, 62 with ACs, 34 with ASCs, and 10 with other rare histopathological types. More extensive patient data are available in Supplementary Table S2.

\section{Mutation Profile}

A total of 92 nonsynonymous somatic mutations were identified in the 285 cervical cancers by Sanger sequencing, including 77 missense substitutions, 1 nonsense substitution, 2 in-frame deletions, 1 frameshift deletion and 11 in-frame fusions (Fig. 1, Supplementary Fig.S1 and Supplementary Table S3). The mutation rates of the tested genes were $27.4 \%$ (49 of 179) in SCC, $33.9 \%$ (21 of 62) in AC, $26.5 \%$ (9 of 34) in ASC and 60\% (6 of $10)$ in the other rare histological subtypes. The mutation rates in $\mathrm{AC}$ and the other rare histological types were higher than that in SCC; however, these differences were not statistically significant $(\mathrm{P}=0.335$ and $\mathrm{P}=0.066$, respectively).

Eighteen $(6.3 \%)$ cancers were found to harbor RAS missense mutations, including $15(5.3 \%)$ in $K R A S$,
2(0.70\%) in NRAS and $1(0.4 \%)$ in HRAS (Fig. 2). Thirtyfive $(12.3 \%)$ cancers harbored PIK3CA mutations, including 32 occurring in exon 9 and 3 in exon 20. Among these mutations, E545K (c.1633G $>$ A) and E542K (c.1624G $>A$ ) were found in $20(7.0 \%)$ and $11(3.8 \%)$ cancers, respectively; H1047R (c.3140A $>$ G) was found in 2 cancers and was associated with an increased response to $\mathrm{PI} 3 \mathrm{~K} / \mathrm{AKT} / \mathrm{mTOR}$ signaling pathway inhibitors in a previous clinical trial [8]. Eight (2.8\%) samples harbored $P T E N$ somatic mutations. No mutations were found in $B R A F$ or $A K T 1$.

HER2, EGFR, FGFR2 and FGFR3 missense substitutions were observed in $10(3.5 \%), 1(0.4 \%)$, $5(1.8 \%)$ and $2(0.7 \%)$ of the cancers, respectively. Two small-cell neuroendocrine carcinomas harbored HER2 inframe deletions in exon 21.

Eleven $(3.9 \%)$ cancers were found to harbor FGFR3-TACC3 fusions. Four variants were identified (Fig. 3). The FGFR1-TACC1, EML4-ALK, CCDC6-RET and KIF5B-RET fusions were not found in any of the cancers.

\section{Clinicopathological characteristics of the patients with mutations}

Table 1 shows the occurrence of the 16 oncogenic mutations in different groups according to different clinicopathological features. RTK mutations were more common in non-squamous carcinomas than in squamous carcinomas ( 15.1 vs. $7.3 \%, \mathrm{P}=0.043$ ). $R A S$ mutations were also more frequent in non-squamous carcinomas than in squamous carcinomas (10.4 vs. $3.9 \%, \mathrm{P}=0.042) . R A S$ mutations were more common in young patients $(<45$ years) than in old patients $(\geq 45$ years $)(13.7 \%$ vs. $7.7 \%$, $\mathrm{P}=0.027)$. RTK mutations tended to be more common in

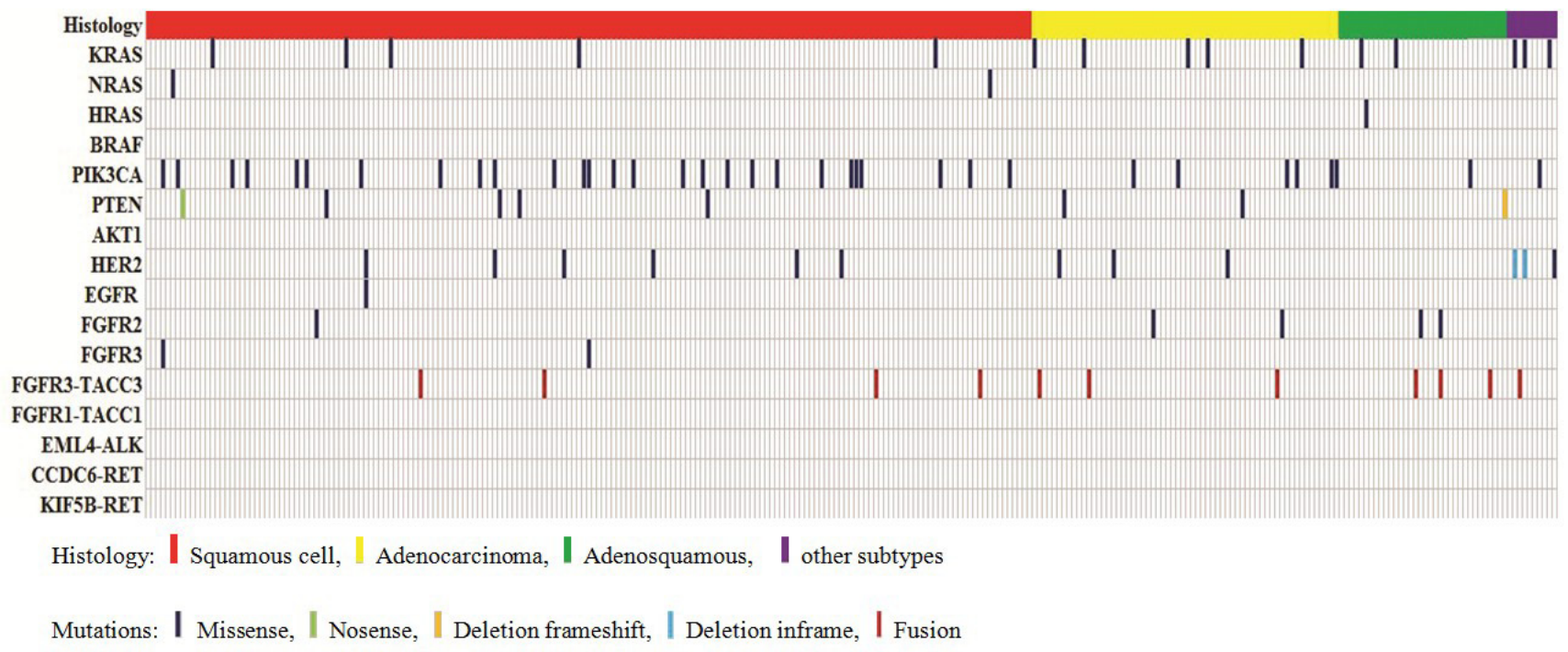

Figure 1: Distribution of mutations of the 16 tested genes in the 285 Chinese cervical cancers. 
Table 1 The prevalence of the 16 oncogenic mutations in different groups according to different clinicopathological features

\begin{tabular}{|c|c|c|c|c|c|c|c|c|c|}
\hline \multirow{2}{*}{ Characteristics } & \multicolumn{3}{|c|}{ PIK3CA/PTEN/AKT } & \multicolumn{3}{|c|}{ RTKs* } & \multicolumn{3}{|c|}{ RAS/RAF } \\
\hline & Wild-type & Mutation & $\mathbf{P}$ & Wild-type & Mutation & $\mathbf{P}$ & Wild-type & Mutation & $\mathbf{P}$ \\
\hline Age (years) & & & 0.065 & & & 0.114 & & & 0.027 \\
\hline$<45$ & 105 & 12 & & 101 & 16 & & 105 & 12 & \\
\hline$\geqslant 45$ & 137 & 31 & & 155 & 13 & & 162 & 6 & \\
\hline Menopause status & & & 0.078 & & & 0.209 & & & 0.441 \\
\hline Yes & 73 & 19 & & 86 & 6 & & 88 & 4 & \\
\hline No & 169 & 24 & & 170 & 23 & & 179 & 14 & \\
\hline Histological type & & & 0.122 & & & 0.043 & & & 0.042 \\
\hline $\mathrm{SCC}$ & 147 & 32 & & 166 & 13 & & 172 & 7 & \\
\hline $\mathrm{AC}+\mathrm{ASC}+$ Others & 95 & 11 & & 90 & 16 & & 95 & 11 & \\
\hline Tumor size & & & 0.716 & & & 1.000 & & & 0.595 \\
\hline$>4 \mathrm{~cm}$ & 67 & 13 & & 72 & 8 & & 74 & 6 & \\
\hline$\leqslant 4 \mathrm{~cm}$ & 175 & 30 & & 184 & 21 & & 193 & 12 & \\
\hline \multicolumn{2}{|c|}{ Depth of myometrial invasion } & & 0.066 & & & 0.829 & & & 1.000 \\
\hline$>1 / 2$ & 167 & 36 & & 183 & 20 & & 190 & 13 & \\
\hline$\leqslant 1 / 2$ & 75 & 7 & & 73 & 9 & & 77 & 5 & \\
\hline LVSI & & & 1.000 & & & 0.209 & & & 0.604 \\
\hline Yes & 78 & 14 & & 86 & 6 & & 85 & 7 & \\
\hline No & 164 & 29 & & 170 & 23 & & 182 & 11 & \\
\hline \multicolumn{2}{|c|}{ Regional lymph node metastasis } & & 0.194 & & & 0.658 & & & 1.000 \\
\hline Yes & 61 & 15 & & 67 & 9 & & 71 & 5 & \\
\hline No & 181 & 28 & & 189 & 20 & & 196 & 13 & \\
\hline \multicolumn{2}{|c|}{ Parametrial involvement } & & 0.674 & & & 1.000 & & & 0.519 \\
\hline Yes & 9 & 2 & & 10 & 1 & & 10 & 1 & \\
\hline No & 233 & 41 & & 246 & 28 & & 257 & 17 & \\
\hline Distant metastasis & & & 0.279 & & & 0.193 & & & 1.000 \\
\hline Yes & 1 & 1 & & 1 & 1 & & 2 & 0 & \\
\hline No & 241 & 42 & & 255 & 28 & & 265 & 18 & \\
\hline
\end{tabular}

* RTKs included EGFR, HER2, FGFR2, FGFR3 mutations and FGFR3-TACC3 fusions.

Fisher's exact test was employed to assess the difference between groups.

young patients, whereas PIK3CA/PTEN/AKT mutations tended to be more common in old patients; however, these differences were not statistically significant. No correlation was found between the 16 oncogenic mutations and disease severity (deep stromal invasion, parametrial invasion, LVSI, lymph node metastasis and distant metastasis). Of the two patients exhibiting distant metastasis, one harbored a PIK3A mutation, whereas the other patient harbored a FGFR3-TACC3 fusion.

\section{Clinical outcome}

Overall, 75.8\% (216 of 285) of the patients received adjuvant therapies after surgery. The median follow-up duration was 35 months (from 20 to 43 months). During follow-up, recurrence information was available for 268 of $285(94.0 \%)$ patients. Forty-nine patients experienced disease recurrence, including 16 patients with known oncogenic mutations. Because the follow-up data were not sufficiently mature, only RFS was assessed according to the mutation status of the tested genes. The 3-year RFS in patients with $R A S$ mutations was $52.3 \%$, which was significantly lower than that in patients with PIK3CA/ 
PTEN mutations $(85.7 \%)$, patients with $R T K$ mutations $(86.1 \%)$, and patients without mutations $(81.4 \%)$. The disease-free survival in patients with mutated PIK3CA/ PTEN or RTK was similar to that of patients without mutations (Fig. 4).

\section{DISCUSSION}

Recently, the development of targeted therapeutics has made it both necessary and valuable to evaluate genetic alterations in various cancers and to subdivide tumors based on the results of molecular genotyping. Currently, drugs that target mutant EGFR, RAF, HER2, $A L K, R E T$ and FGFRs are clinically available [3-7, 9,

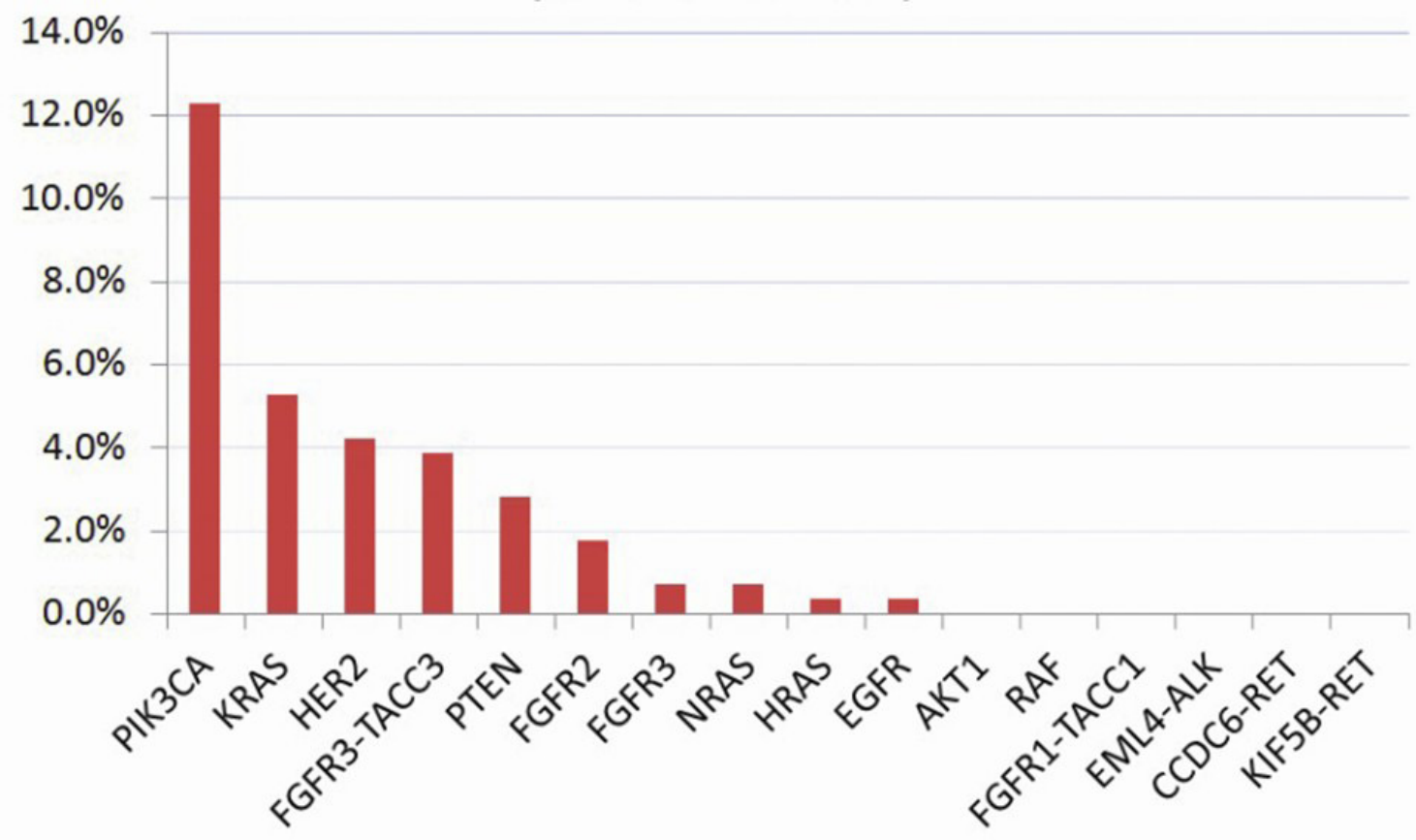

Figure 2: Mutation rates of the 16 tested genes in 285 Chinese cervical cancers

FGFR3-TACC3 variant 1: FGFR3 (residues 1_758) fused with TACC(613_838)

$\operatorname{SCC}(n=3), \operatorname{ASC}(n=1)$, Small cell carcinoma $(n=1)$

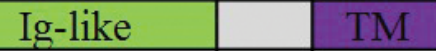

Kinase

758

984

FGFR3-TACC3 variant 2: FGFR3 (residues 1_768) fused with TACC(583_838), with a insertion of 12 residues between them. $\mathrm{AC}(\mathrm{n}=2), \operatorname{ASC}(\mathrm{n}=1)$

\begin{tabular}{l|l|l|} 
Ig-like & & TM \\
\hline
\end{tabular}

Kinase

Coiled-coil

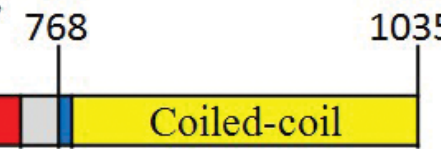

FGFR3-TACC3 variant 3 : FGFR3 (residues 1_758) fused with TACC(648_838)

$\operatorname{AC}(n=1), \operatorname{ASC}(n=1)$

Ig-like

Kinase

758

949

\begin{tabular}{|l|l|l|l|l|l|l|}
\hline & Ig-like & & TM & & Kinase & Coiled-coil \\
\hline
\end{tabular}

FGFR3-TACC3 variant 4 : FGFR3 (residues 1_758) fused with TACC(549_838) $\operatorname{SCC}(\mathrm{n}=1)$

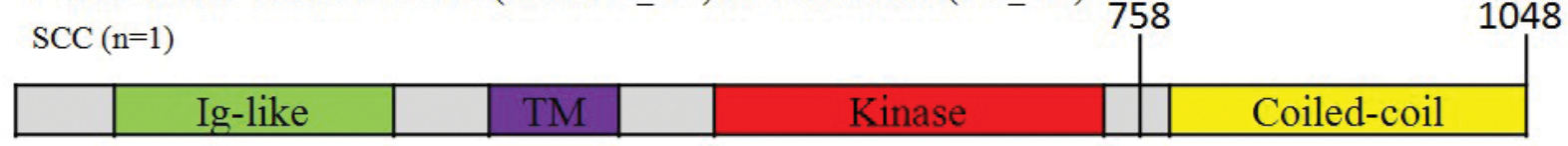

Figure 3: FGFR3-TACC3 fusion variants 
10]. To date, inhibitors of RAS, PIK3CA, PTEN or AKT1 have not been approved by US Food and Drug Administration (FDA); however, inhibitors of downstream targets such as mTOR and MEK have shown therapeutic efficacy in a wide variety of tumors [11-14]. Furthermore, small molecules that irreversibly bind to mutant KRAS (G12C) have been developed and have shown promising antitumor activity in vitro[15]. According to the Catalogue of Somatic Mutations in Cancer (COSMIC) database, the mutation profiles of these genes and their clinicopathological characteristics in cervical cancer are not well established. Oncogenic mutations were examined in samples that were very limited in size (typically less than 100 cases), and the gene mutation status was not concomitantly investigated [16-19]. In addition, it has remained unclear whether patients with cervical cancer harbor gene translocations. To the best of our knowledge, the present study is the first comprehensive and concurrent large-scale analysis of oncogenic mutations in Chinese patients with cervical cancer.
The main findings of this study were that $29.8 \%$ of the patients with cervical cancer harbored oncogenic mutations in the 16 genes assessed, and the mutation rates of PIK3CA/PTEN, RTK and RAS were $15.1 \%, 10.2 \%$, and $6.3 \%$, respectively. $R T K$ and $R A S$ mutations have been found to be more common in histological subtypes of nonSCCs that are resistant to radiation and chemotherapy and are associated with poor survival [20-22]. Approximately one third of the patients with recurrent disease harbored those targetable mutations. Thus, our data provide a clear rationale for clinical trials of targeted inhibitors in patients with cervical cancer especially those advanced and recurrent cases.

Another significant new finding is the discovery of FGFR3-TACC3 fusions in cervical cancer. To our knowledge, this is the first report describing FGFR3TACC3 fusions in cervical cancer. We found that $3.9 \%$ of cervical cancers harbored these intrachromosomal translocations. The fusion proteins encoded by these genes transform normal cell lines, and FGFR kinase inhibitors
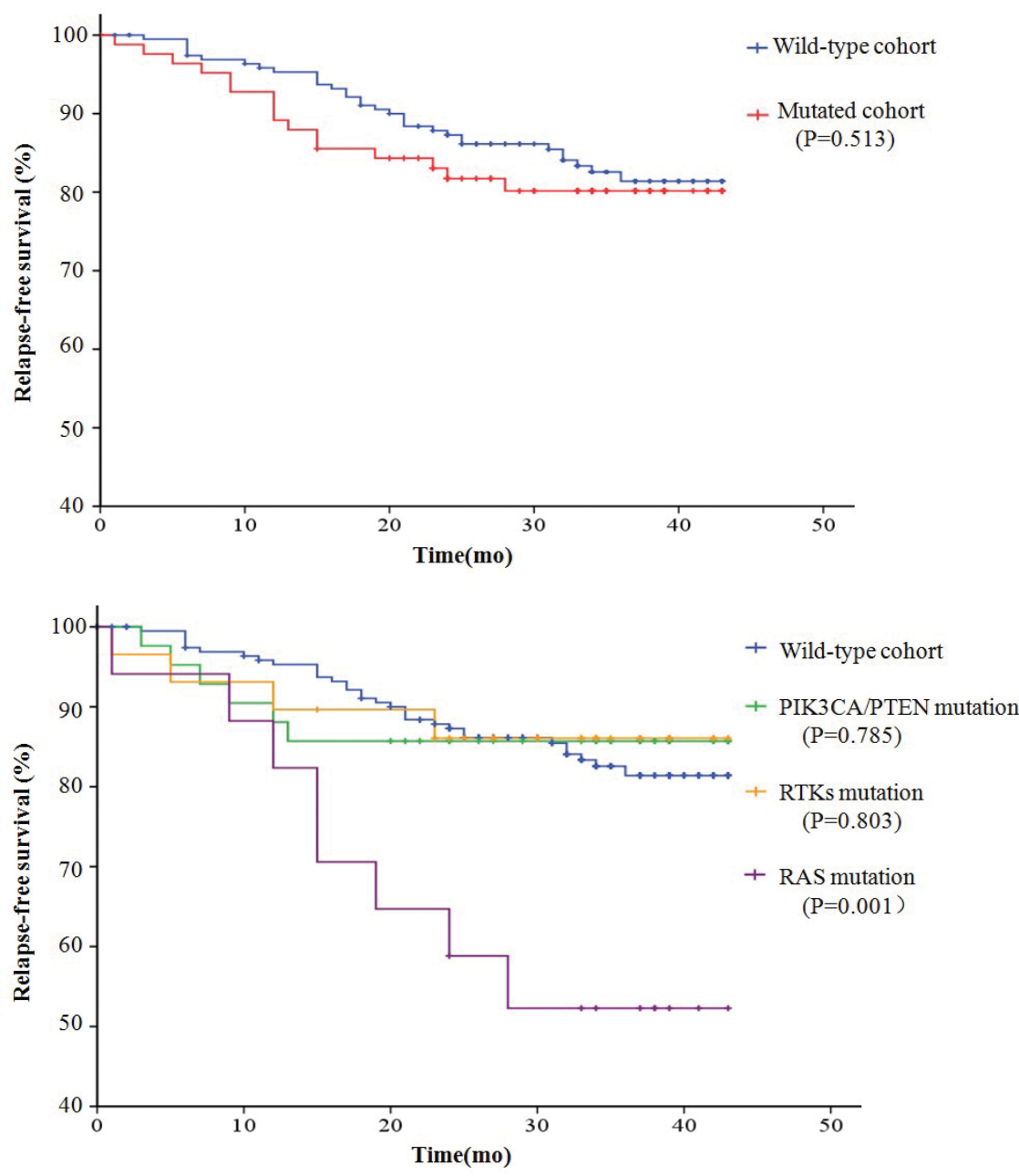

Figure 4: Disease-free survival (RFS) curves plotted by Kaplan-Meier method for the 285 patients based on the mutation status of the 16 tested genes. A. Comparison of RFS in the patients with mutations and the patients without mutations. B. Comparison of RFS in patients with different mutations 
counteract the oncogenic activity of these proteins[23-25]. Patients with tumors that carry FGFR3-TACC3 fusions might potentially benefit from FGFR tyrosine kinase inhibitors, such as pazopanib, ponatinib, PD173074, AZD4547 and BGJ398 [26, 27].

In addition, our results confirm and extend previous findings reported in the literature. The KRAS mutation rate in this study $(5.3 \%)$ was lower than that described in previous studies $(6.3-13.9 \%)(19,28,29)$, which might be a result of the different distribution of histological subtypes or different populations. $B R A F$ mutations in cervical cancer were not observed in this study, as previously reported in a study by Pappa et al.[28]. The frequency of PIK3CA mutations was $12.3 \%$ in this study, which was consistent with COSMIC data and the outcomes of a recent next-generation sequencing study [30]. In the present series of patients who underwent surgery-based multimodality therapy, patients harboring PIK3CA mutations did not have a survival disadvantage. However, McIntyre et al. reported that PIK3CA mutation was strongly associated with worse overall survival in early-stage cervical cancer patients treated with radical chemoradiotherapy [31]. Further investigations are warranted to confirm whether PI3K pathway inhibitors could improve radiotherapy efficacy in cervical cancer patients who have PIK3CA or PTEN mutations. Recurrent HER 2 mutations in cervical cancer were first discovered by Ojesina et al. [30], and our findings confirmed that HER2 mutations were not unusual among cervical malignancies. HER2 in-frame deletions in small-cell neuroendocrine carcinomas warranted further investigation and functional validation. Our study suggested that somatic mutations in EGFR, FGFR2, and FGFR3 are rare in cervical cancers; this result was similar to the findings of previous studies $[16,17,32]$.

Although many oncogenic gene mutations were analyzed in this study, there were some limitations. First, protein expression and gene copy number changes were not examined in this study, which might have prevented us from identifying patients who would be suitable for targeted therapy, such as those with HER2 or EGFR overexpression. Second, not all mutations were located in well-known hotspots; thus, some of the mutations identified in this study might serve as 'passenger mutations'. Third, the primers used for the translocation tests did not cover all isoforms of the tested genes. We could therefore not exclude the possibility that some gene fusions might have been missed.

In summary, our data reveal that a considerable proportion of patients with cervical cancers harbor known druggable mutations and might benefit from targeted therapy. These findings provide support for clinical trials involving PI3K pathway inhibitors, tyrosine kinase inhibitors (TKIs) and MAPK pathway inhibitors in patients with cervical cancer detected by targeted molecular screening.

\section{METHODS}

\section{Patients and specimens}

This research was approved by the Institutional Review Board of Fudan University Shanghai Cancer Center (FUSCC). All patients provided written informed consent. A total of 285 Chinese women were included in this study after it was determined that they met the following criteria: pathologically confirmed primary cervical squamous cell carcinoma (SCC), adenocarcinoma (AC), adenosquamous carcinoma (ASC) or small cell carcinoma; stage IB1-IIA2 disease according to the International Federation of Gynecology and Obstetrics (FIGO) staging system; no neoadjuvant chemotherapy or radiation; and no history of pre-operative cone biopsies. Cervical tumor specimens were collected during radical hysterectomy procedures from January 2011 to December 2012. Each specimen was cut into two blocks. One was fixed in formalin, embedded in paraffin, sectioned and stained with Hematoxylin \& Eosin for histological examination. The other was stored in RNAlater solution (Ambion) at $-80^{\circ} \mathrm{C}$ for mutational analysis. Only specimens in which tumor cells accounted for more than $50 \%$ of the whole tissue were processed to mutational analysis. Histopathological characteristics and tumor contents were confirmed by two pathologists (X Shen and W Yang). Clinical and pathological data were prospectively collected and included the following: age, menopause status, histological subtype, FIGO stage, tumor size, depth of invasion, lymphovascular space involvement (LVSI), lymph node status, distant metastasis, parametrial involvement and tumor differentiation. The patients were followed up in the clinic or by telephone to determine disease recurrence.

\section{Mutational analyses}

RNA and genomic DNA were extracted from the tumor tissues according to the standard protocols provided with the DNA/RNA Isolation Kit (Tiangen Biotech); $2 \mu \mathrm{g}$ of total RNA was reverse-transcribed into singlestranded cDNA using an M-MLV Reverse Transcriptase Kit(Invitrogen). The presence of mutations was determined in $N R A S$ (exons 1-3), KRAS (all exons), HRAS (exons 1-3), BRAF (exons 13-16), PIK3CA (exons 8-11,18-20), PTEN (exons 5-9), AKT1 (exons 1-3), HER2 (exons 5-12, 16-25), EGFR (exons 18-22), FGFR2(exons 5-9,10-15) and FGFR3 (exons 5-9) as well as in FGFR3-TACC3, FGFR1-TACC1, EML4-ALK, CCDC6-RET and KIF5B$R E T$ fusions. cDNA was PCR amplified with KOD plus neo DNA polymerase (Toyobo). The PCR products were sequenced from both ends using Sanger sequencing. All mutations were confirmed by an additional independent 
PCR. The primers and the detailed PCR protocol are provided in Supplementary Table S1. Germline mutations were excluded by sequencing the DNA extracted from paired peripheral blood cells or corresponding formalinfixed and paraffin-embedded normal uterus corpus tissues . Paraffin embedded tissues were retrieved from archival specimens stored in pathology department and reviewed by the two pathologists to exclude tumor involvements.

\section{Statistical analysis}

The association between mutations and clinicopathological characteristics was analyzed by Fisher's exact test. Relapse-free survival (RFS) was calculated using the Kaplan-Meier method, and the differences between the groups were determined using the log-rank test. The 2-sided significance level was set at $\mathrm{P}<0.05$. The data were analyzed using IBM SPSS Statistics 19 (IBM Inc.).

\section{ACKNOWLEDGEMENTS}

This study was supported by a grant from the Shanghai Natural Science Foundation (09ZR1407000)

\section{CONFLICT OF INTEREST STATEMENT}

The authors indicate no conflict of interest.

\section{REFERENCES}

1. Chen W, Zheng R, Zhang S, Zhao P, Zeng H, Zou X, He J. Annual report on status of cancer in China, 2010. Chin J Cancer Res. 2014;26:48-58.

2. Lorusso D, Petrelli F, Coinu A, Raspagliesi F, Barni S. A systematic review comparing cisplatin and carboplatin plus paclitaxel-based chemotherapy for recurrent or metastatic cervical cancer. Gynecol Oncol. 2014;133:117-23.

3. Mok TS, Wu YL, Thongprasert S, Yang CH, Chu DT, Saijo N, Sunpaweravong P, Han B, Margono B, Ichinose Y, Nishiwaki Y, Ohe Y, Yang JJ, et al. Gefitinib or carboplatin-paclitaxel in pulmonary adenocarcinoma. N Engl J Med. 2009;361:947-57.

4. Sequist LV, Yang JC, Yamamoto N, O’Byrne K, Hirsh V, Mok T, Geater SL, Orlov S, Tsai CM, Boyer M, Su WC, Bennouna J, Kato T, et al. Phase III study of afatinib or cisplatin plus pemetrexed in patients with metastatic lung adenocarcinoma with EGFR mutations. J Clin Oncol. 2013;31:3327-34.

5. Chapman PB, Hauschild A, Robert C, Haanen JB, Ascierto P, Larkin J, Dummer R, Garbe C, Testori A, Maio M, Hogg D, Lorigan P, Lebbe C, et al. Improved survival with vemurafenib in melanoma with BRAF V600E mutation. N
Engl J Med. 2011;364:2507-16.

6. Mazieres J, Peters S, Lepage B, Cortot AB, Barlesi F, Beau-Faller M, Besse B, Blons H, Mansuet-Lupo A, Urban T, Moro-Sibilot D, Dansin E, Chouaid C, et al. Lung cancer that harbors an HER2 mutation: epidemiologic characteristics and therapeutic perspectives. J Clin Oncol. 2013;31:1997-2003.

7. Butrynski JE, D'Adamo DR, Hornick JL, Dal Cin P, Antonescu CR, Jhanwar SC, Ladanyi M, Capelletti M, Rodig SJ, Ramaiya N, Kwak EL, Clark JW, Wilner $\mathrm{KD}$, et al. Crizotinib in ALK-rearranged inflammatory myofibroblastic tumor. N Engl J Med. 2010;363:1727-33.

8. Janku F, Wheler JJ, Naing A, Falchook GS, Hong DS, Stepanek VM, Fu S, Piha-Paul SA, Lee JJ, Luthra R, Tsimberidou AM, Kurzrock R. PIK3CA mutation H1047R is associated with response to $\mathrm{PI} 3 \mathrm{~K} / \mathrm{AKT} / \mathrm{mTOR}$ signaling pathway inhibitors in early-phase clinical trials. Cancer Res. 2013;73:276-84.

9. Drilon A, Wang L, Hasanovic A, Suehara Y, Lipson D, Stephens P, Ross J, Miller V, Ginsberg M, Zakowski MF, Kris MG, Ladanyi M, Rizvi N. Response to Cabozantinib in patients with RET fusion-positive lung adenocarcinomas. Cancer Discov. 2013;3:630-5.

10. Borad MJ, Champion MD, Egan JB, Liang WS, Fonseca R, Bryce AH, McCullough AE, Barrett MT, Hunt K, Patel MD, Young SW, Collins JM, Silva AC, et al. Integrated genomic characterization reveals novel, therapeutically relevant drug targets in FGFR and EGFR pathways in sporadic intrahepatic cholangiocarcinoma. PLoS Genet. 2014;10:e1004135.

11. Hess G, Herbrecht R, Romaguera J, Verhoef G, Crump M, Gisselbrecht C, Laurell A, Offner F, Strahs A, Berkenblit A, Hanushevsky O, Clancy J, Hewes B, et al. Phase III study to evaluate temsirolimus compared with investigator's choice therapy for the treatment of relapsed or refractory mantle cell lymphoma. J Clin Oncol. 2009;27:3822-9.

12. Janku F, Wheler JJ, Westin SN, Moulder SL, Naing A, Tsimberidou AM, Fu S, Falchook GS, Hong DS, GarridoLaguna I, Luthra R, Lee JJ, Lu KH, et al. PI3K/AKT/ mTOR inhibitors in patients with breast and gynecologic malignancies harboring PIK3CA mutations. J Clin Oncol. 2012;30:777-82.

13. Andre F, O'Regan R, Ozguroglu M, Toi M, Xu B, Jerusalem G, Masuda N, Wilks S, Arena F, Isaacs C, Yap YS, Papai Z, Lang I, et al. Everolimus for women with trastuzumab-resistant, HER2-positive, advanced breast cancer (BOLERO-3): a randomised, double-blind, placebocontrolled phase 3 trial. Lancet Oncol. 2014; 15:580-91.

14. Janne PA, Shaw AT, Pereira JR, Jeannin G, Vansteenkiste J, Barrios C, Franke FA, Grinsted L, Zazulina V, Smith P, Smith I, Crino L. Selumetinib plus docetaxel for KRASmutant advanced non-small-cell lung cancer: a randomised, multicentre, placebo-controlled, phase 2 study. Lancet Oncol. 2013;14:38-47.

15. Ostrem JM, Peters U, Sos ML, Wells JA, Shokat KM. 
K-Ras(G12C) inhibitors allosterically control GTP affinity and effector interactions. Nature. 2013;503:548-51.

16. Wu R, Connolly D, Ngelangel C, Bosch FX, Munoz N, Cho KR. Somatic mutations of fibroblast growth factor receptor 3 (FGFR3) are uncommon in carcinomas of the uterine cervix. Oncogene. 2000;19:5543-6.

17. Arias-Pulido H, Joste N, Chavez A, Muller CY, Dai D, Smith HO, Verschraegen CF. Absence of epidermal growth factor receptor mutations in cervical cancer. Int J Gynecol Cancer. 2008; 18:749-54.

18. Janku F, Lee JJ, Tsimberidou AM, Hong DS, Naing A, Falchook GS, Fu S, Luthra R, Garrido-Laguna I, Kurzrock R. PIK3CA mutations frequently coexist with RAS and BRAF mutations in patients with advanced cancers. PLoS One. 2011;6:e22769.

19. Wright AA, Howitt BE, Myers AP, Dahlberg SE, Palescandolo E, Van Hummelen P, MacConaill LE, Shoni M, Wagle N, Jones RT, Quick CM, Laury A, Katz IT, et al. Oncogenic mutations in cervical cancer: genomic differences between adenocarcinomas and squamous cell carcinomas of the cervix. Cancer. 2013;119:3776-83.

20. Galic V, Herzog TJ, Lewin SN, Neugut AI, Burke WM, Lu YS, Hershman DL, Wright JD. Prognostic significance of adenocarcinoma histology in women with cervical cancer. Gynecol Oncol. 2012;125:287-91.

21. Noh JM, Park W, Kim YS, Kim JY, Kim HJ, Kim J, Kim JH, Yoon MS, Choi JH, Yoon WS, Kim JY, Huh SJ. Comparison of clinical outcomes of adenocarcinoma and adenosquamous carcinoma in uterine cervical cancer patients receiving surgical resection followed by radiotherapy: a multicenter retrospective study (KROG 1310). Gynecol Oncol. 2014;132:618-23.

22. McCann GA, Boutsicaris CE, Preston MM, Backes FJ, Eisenhauer EL, Fowler JM, Cohn DE, Copeland LJ, Salani R, O'Malley DM. Neuroendocrine carcinoma of the uterine cervix: the role of multimodality therapy in early-stage disease. Gynecol Oncol.. 2013;129:135-9.

23. Parker BC, Annala MJ, Cogdell DE, Granberg KJ, Sun Y, Ji P, Li X, Gumin J, Zheng H, Hu L, Yli-Harja O, Haapasalo $\mathrm{H}$, Visakorpi $\mathrm{T}$, et al. The tumorigenic FGFR3-TACC3 gene fusion escapes miR-99a regulation in glioblastoma. $\mathrm{J}$ Clin Invest. 2013;123:855-65.

24. Singh D, Chan JM, Zoppoli P, Niola F, Sullivan R, Castano A, Liu EM, Reichel J, Porrati P, Pellegatta S, Qiu K, Gao Z, Ceccarelli M, et al. Transforming fusions of FGFR and TACC genes in human glioblastoma. Science. 2012;337:1231-5.

25. Wu YM, Su F, Kalyana-Sundaram S, Khazanov N, Ateeq B, Cao X, Lonigro RJ, Vats P, Wang R, Lin SF, Cheng AJ, Kunju LP, Siddiqui J, et al. Identification of targetable FGFR gene fusions in diverse cancers. Cancer Discov. 2013;3:636-47.

26. Sabnis AJ, Bivona TG. FGFR fusions in the driver's seat. Cancer Discov. 2013;3:607-9.
27. Gozgit JM, Wong MJ, Moran L, Wardwell S, Mohemmad QK, Narasimhan NI, Shakespeare WC, Wang F, Clackson T, Rivera VM. Ponatinib (AP24534), a multitargeted panFGFR inhibitor with activity in multiple FGFR-amplified or mutated cancer models. Mol Cancer Ther. 2012;11:690-9.

28. Pappa KI, Choleza M, Markaki S, Giannikaki E, Kyroudi A, Vlachos G, Voulgaris Z, Anagnou NP. Consistent absence of BRAF mutations in cervical and endometrial cancer despite KRAS mutation status. Gynecol Oncol. 2006;100:596-600.

29. Kang S, Kim HS, Seo SS, Park SY, Sidransky D, Dong SM. Inverse correlation between RASSF1A hypermethylation, KRAS and BRAF mutations in cervical adenocarcinoma. Gynecol Oncol. 2007;105:662-6.

30. Ojesina AI, Lichtenstein L, Freeman SS, Pedamallu CS, Imaz-Rosshandler I, Pugh TJ, Cherniack AD, Ambrogio L, Cibulskis K, Bertelsen B, Romero-Cordoba S, Trevino V, Vazquez-Santillan K, et al. Landscape of genomic alterations in cervical carcinomas. Nature. 2014;506:371-5.

31. McIntyre JB, Wu JS, Craighead PS, Phan T, Kobel M, LeesMiller SP, Ghatage P, Magliocco AM, Doll CM. PIK3CA mutational status and overall survival in patients with cervical cancer treated with radical chemoradiotherapy. Gynecol Oncol. 2013;128:409-14.

32. Sibley K, Stern P, Knowles MA. Frequency of fibroblast growth factor receptor 3 mutations in sporadic tumours. Oncogene. 2001;20:4416-8. 